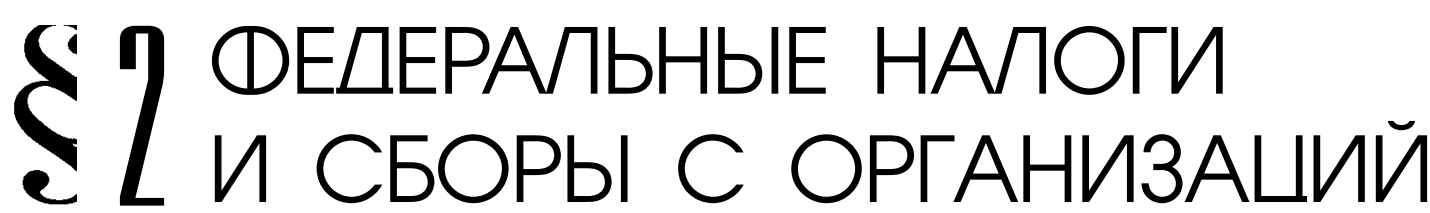

И.В. Оробинская

\section{ХАРАКТЕРИСТИКА НАЛОГОВОГО ПОТЕНЦИАЛА СУБЪЕКТОВ АГРАРНОГО СЕКТОРА РОССИИ НА ПРИМЕРЕ ОБЛАСТЕЙ ЦЧР}

Аннотация: Эффективная реализация и рост налогового потенциала аграрного сектора субъектов Российской Федерации следует считать важнейшим условием динамичного развития экономики России. Предметом исследования является анализ налогового потенциала на примере областей ЦЧР. Следует отметить, что в российской экономике последние несколько лет сохранялись высокие темпы роста большинства основных макроэкономических показателей, что способствовало увеличению налоговых поступлений в бюджетную систему РФ, и, в свою очередь, положительно отражалось на исполнении консолидированного и федерального бюджетов РФ.По нашему мнению, обеспечение последовательного развития налогового потенциала регионов будет способствовать росту их финансовой самостоятельности и повышению уровня социально-экономического роста. Методологической основой исследования послужили фундаментальные концепции, представленные в трудах отечественных и зарубежных ученых, законодательные и нормативно-правовые акты госу-дарственных органов власти, федеральные законы, материалы научно-практических конференций, затрагивающие вопросы налогообложения субъектов аграрного сектора России.В работе использованы абстрактно-логический, монографический, статистико-экономический и другие методы экономических исследований. Сравнительный анализ показал, что предельная величина фискального бремени в аграрной срере экономики, и ее влияние связаны не только с величиной совокупного обложения, но и с эффрективностью производства и финансовым состоянием предприятия. Эффективность производства задается объемом и структурой затрат, сроком их окупаемости и полученной прибылью, что в значительной степени обусловлено сферой деятельности предпринимателя. Следовательно, предел налогообложения должен определяться с учетом отраслевой принадлежности хозяйствующих субъектов и связанных с этим объективных факторов объема и структуры расходов, скорости оборота капитала.Таким образом, для стимулирования предпринимательской деятельности в аграрном секторе необходимо достижение эффективности использования налоговых инструментов. При определении предела обложения следует учитывать совокупное фискальное бремя и платежеспособность различных категорий хозяйствующих субъектов.

Ключевые слова: Налоговый потенциал, Аграрный сектор, ЦЧР, Налоговые доходы, Бюджетная обеспеченность, Сельское хозяйство, Задолженнсть по налогам, НДС, Налог на прибыль, ЕСХH. 
Э ффективная реализация и рост налогового потенциала аграрного сектора субъектов Российской Федерации по нашему мнению следует считать важнейшим условием динамичного развития экономики России. Так, обеспечение последовательного развития налогового потенциала регионов будет способствовать росту их финансовой самостоятельности и повышению уровня социально-экономического роста.

Определенные положительные перемены в аграрной экономике (рост инвестиций в основной капитал, субсидирование процентной ставки по кредитам, реструктуризация кредиторской задолженности производителей, расширение использования лизинга сельскохозяйственной техники и др.) не привели к изменению трех главных негативных тенденций, а именно:

- продолжает ухудшаться материальнотехническая база сельского хозяйства, несмотря на улучшение финансового положения сельскохозяйственных организаций;

- непомерно высокими остаются долги сельскохозяйственных товаропроизводителей;

- $\quad$ продолжается неэквивалентный обмен произведенной сельскохозяйственной продукции на промышленные ресурсы, используемые в сельском хозяйстве.

Следует отметить, что в российской экономике последние несколько лет (2006 2013 г.) сохранялись высокие темпы роста большинства основных макроэкономических показателей, что способствовало увеличению налоговых поступлений в бюджетную систему РФ, и, в свою очередь, положительно отражалось на исполнении консолидированного и федерального бюджетов РФ.

Так, в консолидированный бюджет РФ по оперативным данным Федеральной налоговой службы (ФНС), в 2011 г. поступило 56644 млрд. руб., а уже в 2013 г. 66689 млрд. руб. налогов, сборов и иных обязательных платежей, администрируемых налоговыми органами (рис.1).

Особый интерес вызывает удельный вес налоговых поступлений на региональном уровне. Так, бюджетная обеспеченность ЦЧР ниже 50\% от среднероссийской, а индекс налогового потенциала один из самых низких по стране (табл. 1).

Таблища 1.

\section{Бюджетная обеспеченность ЦЧР} в 2013 г.

\begin{tabular}{|l|c|c|c|}
\hline & $\begin{array}{c}\text { Индекс } \\
\text { налого- } \\
\text { вого по- } \\
\text { тенциала }\end{array}$ & $\begin{array}{c}\text { Индекс } \\
\text { бюд- } \\
\text { расхо- } \\
\text { дов }\end{array}$ & $\begin{array}{c}\text { Уровень } \\
\text { реальной } \\
\text { бюджетной } \\
\text { обеспечен- } \\
\text { ности }\end{array}$ \\
\hline РФ & 1,0000 & 1,00 & 1,00 \\
\hline $\begin{array}{l}\text { Белгород- } \\
\text { ская обл. }\end{array}$ & 0,7 & 0,8 & 0,9 \\
\hline $\begin{array}{l}\text { Воронеж- } \\
\text { ская обл. }\end{array}$ & 0,6 & 0,9 & 0,6 \\
\hline $\begin{array}{l}\text { Липецкая } \\
\text { обл. }\end{array}$ & 0,5 & 0,9 & 0,7 \\
\hline
\end{tabular}

Доходы региональных бюджетов областей ЦЧР складываются из налоговых поступлений, доходов от деятельности государственных предприятий, от сдачи в наем государственного имущества, безвозмездных перечислений федерального бюджета (субсидий, субвенций и дотаций). Налоговые доходы составляют 50-70\% доходов бюджетов регионов, вторыми по значимости являются безвозмездные поступления в бюджет регионов (до 30\% доходов), остальные неналоговые доходы составляют незначительную часть доходов бюджетов.

Нам представляется, что индикатором прибыльности предприятий, работающих в отраслях ЦЧР, является величина налоговых 


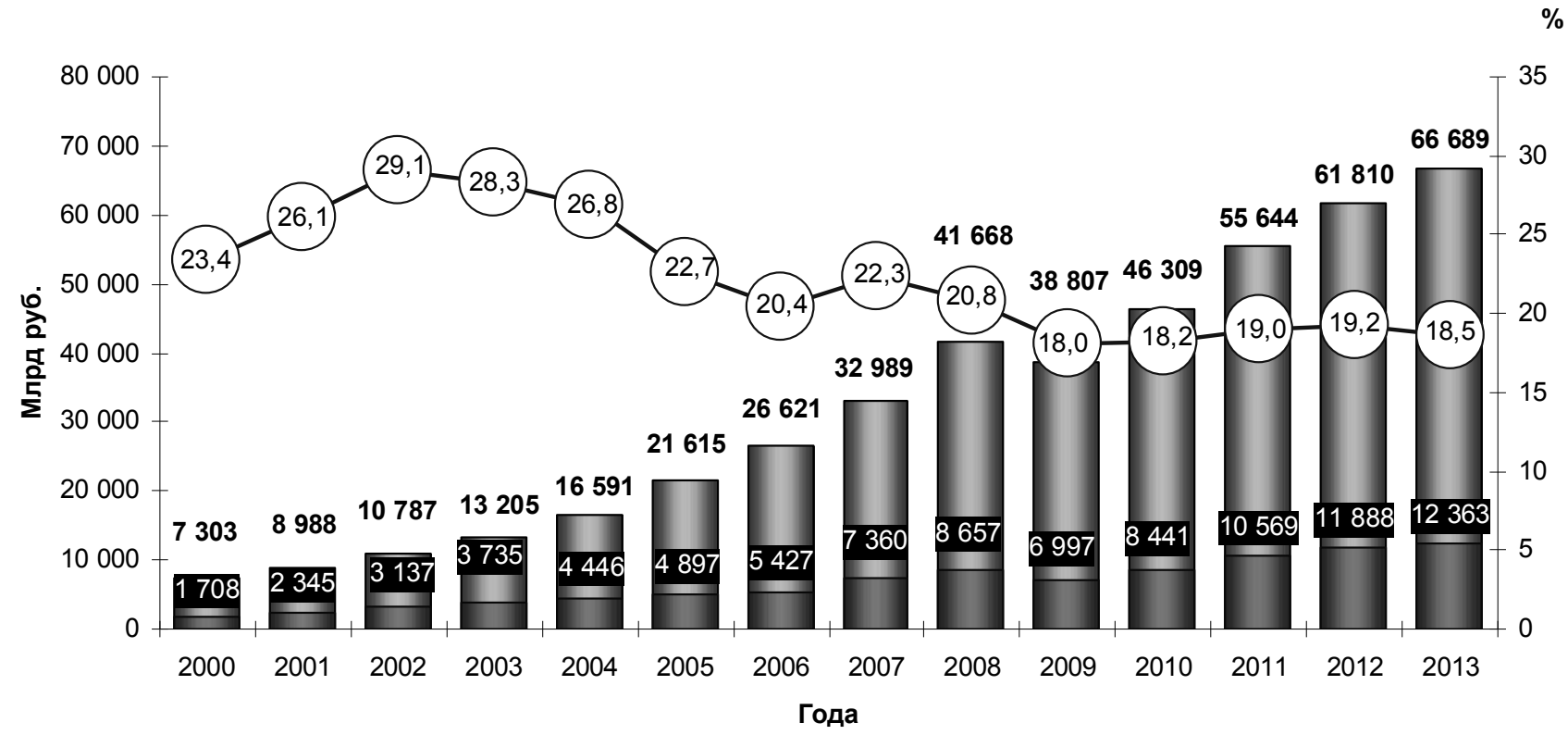

ШВП в текущих ценах, млрд руб. س налоговые доходы, млрд руб. —- - налоговые доходы в \% от ВВП

Рисунок 1. Динамика налоговых доходов в федеральном бюджете и бюджетах субъектов РФ (млрд. р.) Источник: www.nalog.ru

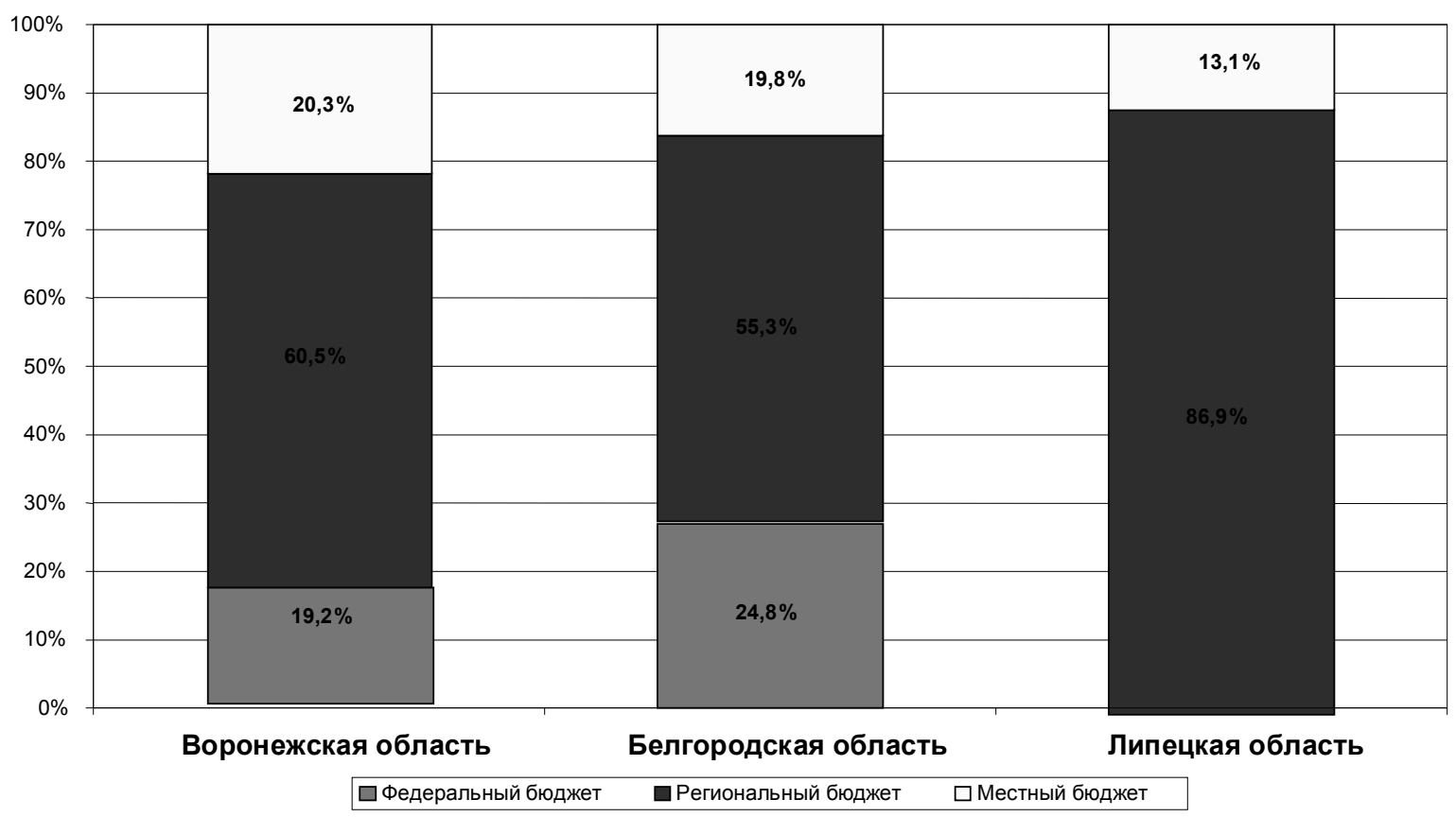

Рисунок 2. Структура налоговых поступлений в бюджеты различных уровней областей ЦЧР в 2013 г.

доходов бюджетов регионов. Высокий объем налоговых доходов делает регионы более стабильными и менее рисковыми с точки зрения инвестиционных вложений (рис. 2).
Так, например в структуре доходов на налоговые поступления в 2011 г. приходилось 66,5\%, а уже в 2013 г. - 95\%. В 2011 г. объем налоговых доходов, мобилизиру- 
емых в Воронежской области, составил 52 млрд.руб., а к 2014 г. вырос в 1,3 раза и составил 71 млрд.руб. Основные статьи доходов областей ЦЧР в разрезе основных налогов представлены в таблице 2.

Основу налоговых доходов в 2013 г. составляли НДС (12\% Воронежская область, $15 \%$ - Белгородская область величины налоговых поступлений) и налог на прибыль предприятий (15\% и 15\% соответственно). В Липецкой же области напротив НДС находится на уровне возмещения, а налог на прибыль составляет 11\% налоговых доходов бюджета, что может свидетельствовать об инвестиционной привлекательности данного региона.

Следует отметить, что на протяжении нескольких лет поступление почти $68 \%$ всех налогов и сборов в бюджетную систему, как России в целом, так и на уровне субъектов РФ, было обеспечено такими отраслями как промышленность, торговля, общественное питание, материальнотехническое снабжение и сбыт, транспорт и связь (табл.3). От отрасли сельского хозяйства в бюджет РФ поступает в среднем не более $0,8 \%$. Связано это с тем, что ввиду объективных причин более половины современных аграрных формирований находятся в весьма тяжелых финансовых условиях: уровень заработной платы почти в три раза ниже чем в среднем по стране, низкий уровень и большая изношенность материально-технической базы, и поэтому отчисление от прибыли, доходов физических лиц, социальных налогов, налога на имущества весьма незначительны (табл.3).

Льготный режим налогообложения в сельском хозяйстве, а также тот факт, что в валовой продукции сектора достаточно высока доля продукции личных подсобных хозяйств населения, которые не облагаются налогами, приводит к тому, что вклад этого сектора в общий объем собираемых налогов меньше, чем в ВВП.

В связи с тем, что снижение налогового бремени в ходе налоговой реформы касалось тех налогов, которые сельское хозяйство не платило, то в этом секторе экономики налоговая нагрузка снизилась в наименьшей степени.

Таким образом, реальная налоговая нагрузка по отраслям экономики неравномерна ни по России в целом, ни регионам в частности. В наиболее выгодных условиях находились финансовая сфера, торговля и обслуживание, поскольку у них срок оборота капитала меньше и окупаемость затрат быстрее, что нельзя сказать про сельское хозяйство. Здесь напротив затраты велики, а срок их окупаемости более длительный.

Следует отметить, если в налоговых доходах бюджета РФ основную долю составляют такие налоги как НДС и налог на прибыль, то в сельском хозяйстве их удельный вес незначителен (табл.3).

Мы считаем, что с переходом на ЕСХН с 2003 г. доля НДС и налога на прибыль уменьшается, но не за счет роста доли $\mathrm{ECXH}$, а за счет возникновения налога на имущество (с организаций, не перешедших на ECXH) и роста прочих налогов на сельское хозяйство (водного, транспортного, сборов за пользование объектами животного мира и пр., местных налогов и сборов). Наряду с этим, следует учитывать тот факт, что реализация большинства продовольственных товаров (мясо, молоко, зерно) облагается по ставке НДС 10\%. В то же время сельхозпредприятия приобретают многие товары (сельхозтехника, ГСМ и т.д.), которые облагаются НДС по ставке 18\%. Поэтому вычеты по данному налогу у сельхозпредприятий, как правило, превышает сумму начислений, что особенно просматривается на уровне регионов. 
DOI: $10.7256 / 1812-8688.2014 .6 .11783$

При цитировании этой статьи сноска на doi обязательна

Федеральные налоги и сборы с организаций

Таблица 2.

\section{Структура налоговых доходов в консолидированном}

бюджете областей ЦЧР., млрд. руб.

\begin{tabular}{|c|c|c|c|c|c|c|c|c|c|}
\hline \multirow{3}{*}{ Показатели } & \multicolumn{3}{|c|}{ Воронежская область } & \multicolumn{3}{|c|}{ Липецкая область } & \multicolumn{3}{|c|}{ Белгородская область } \\
\hline & \multicolumn{9}{|c|}{ Года } \\
\hline & 2011 & 2012 & 2013 & 2011 & 2012 & 2013 & 2011 & 2012 & 2013 \\
\hline Всего налогов: & 52 & 64 & 71 & 21 & 24 & 28 & 68 & 66 & 62 \\
\hline $\begin{array}{l}\text { Налог на прибыль } \\
\text { организаций }\end{array}$ & 13 & 16 & 15 & 13 & 11 & 11 & 28 & 21 & 15 \\
\hline НДС & 9 & 9 & 12 & -11 & -9 & -7 & 13 & 14 & 15 \\
\hline Акцизы & 2 & 2 & 3 & 0,9 & 1 & 2 & 0,9 & 0,9 & 2 \\
\hline $\begin{array}{l}\text { Налоги на } \\
\text { имущество }\end{array}$ & 7 & 10 & 11 & 6 & 7 & 8 & 9 & 10 & 11 \\
\hline Земельный налог & 2 & 2 & 2 & 2 & 2 & 2 & 3 & 3 & 3 \\
\hline $\begin{array}{l}\text { Специальные } \\
\text { налоговые } \\
\text { режимы }\end{array}$ & 2 & 4 & 3 & 1 & 1 & 2 & 2 & 2 & 2 \\
\hline Прочие налоги & 17 & 21 & 25 & 9,1 & 11 & 10 & 12,1 & 15,1 & 14 \\
\hline
\end{tabular}

Источник: www.nalog.ru

Объем поступлений налогов в бюджетную систему РФ ЦЧР

Таблица 3. по основным видам экономической деятельности, млрд. руб.

\begin{tabular}{|c|c|c|c|c|c|c|c|c|}
\hline 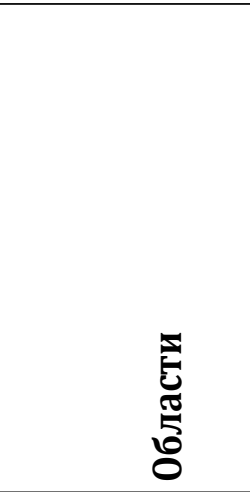 & 疍 & 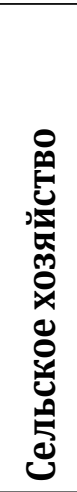 & 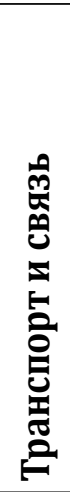 & 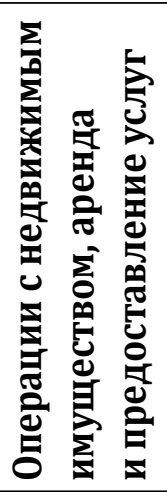 & 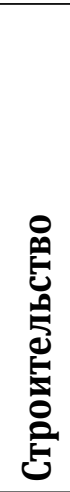 & 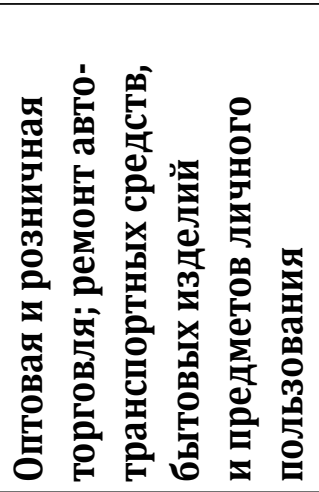 & 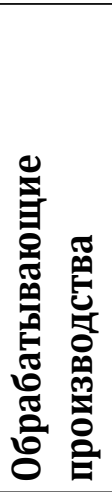 & 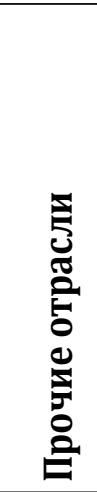 \\
\hline \multirow{3}{*}{ Белгородская } & 2011 & 2,8 & 2,9 & 4,1 & 5,2 & 3,5 & 11,8 & 37,7 \\
\hline & 2012 & 3,7 & 2,8 & 4,2 & 5,4 & 4,5 & 15,2 & 30,2 \\
\hline & 2013 & 4,4 & 2,8 & 4,0 & 5,0 & 5,8 & 13,5 & 26,5 \\
\hline \multirow{3}{*}{ Воронежская } & 2011 & 0,7 & 5,3 & 6,4 & 3,5 & 9,0 & 11,6 & 15,48 \\
\hline & 2012 & 0,6 & 6,9 & 8,9 & 4,3 & 11,6 & 11,7 & 21,2 \\
\hline & 2013 & 0,3 & 6,1 & 11,0 & 4,7 & 11,3 & 13,1 & 24,5 \\
\hline \multirow{3}{*}{ Липецкая } & 2011 & 0,5 & 2,3 & 2,8 & 2,7 & 4,4 & 0,2 & 8,1 \\
\hline & 2012 & 0,6 & 2,4 & 2,6 & 2,6 & 5,2 & 1,1 & 9,5 \\
\hline & 2013 & 0,5 & 2,3 & 3,5 & 2,2 & 5,6 & 3,6 & 6,3 \\
\hline
\end{tabular}




\section{Структура налоговых платежей в сельском хозяйстве областей ЦЧР, млн.руб.}

\begin{tabular}{|l|c|c|c|c|c|c|c|c|c|}
\hline & \multicolumn{3}{|c|}{ Воронежская область } & \multicolumn{3}{c|}{ Липецкая область } & \multicolumn{3}{c|}{ Белгородская область } \\
\cline { 2 - 12 } & $\mathbf{2 0 1 1}$ г. & $\mathbf{2 0 1 2}$ г. & $\mathbf{2 0 1 3}$ г. & $\mathbf{2 0 1 1}$ г. & $\mathbf{2 0 1 2}$ г. & $\mathbf{2 0 1 3}$ г. & $\mathbf{2 0 1 1}$ г. & $\mathbf{2 0 1 2}$ г. & $\mathbf{2 0 1 3}$ г. \\
\hline Всего налогов: & 0,7 & 0,6 & 0,3 & 0,5 & 0,6 & 0,5 & 2,8 & 3,7 & 4,4 \\
\hline $\begin{array}{l}\text { Налог на } \\
\begin{array}{l}\text { прибыль } \\
\text { организаций }\end{array}\end{array}$ & 0,2 & 0,1 & 0,1 & 0,05 & 0,06 & 0,04 & 0,3 & 0,7 & 0,4 \\
\hline НДС & $-0,9$ & $-1,8$ & $-1,7$ & $-0,4$ & $-0,4$ & $-0,5$ & $-0,7$ & $-0,8$ & 0,02 \\
\hline $\begin{array}{l}\text { Налоги и сборы } \\
\begin{array}{l}\text { за пользование } \\
\text { природными } \\
\text { ресурсами }\end{array}\end{array}$ & 0,003 & 0,002 & 0,002 & 0,001 & 0,001 & 0,001 & 0,007 & 0,008 & 0,007 \\
\hline НДФл & 0,9 & 1,2 & 1,3 & 0,9 & 0,7 & 0,7 & 1,6 & 1,9 & 2,09 \\
\hline $\begin{array}{l}\text { Специальные } \\
\text { налоговые } \\
\text { режимы }\end{array}$ & 0,2 & 0,1 & 0,2 & 0,03 & 0,02 & 0,05 & 0,09 & 0,05 & 0,06 \\
\hline Прочие налоги & 0,1 & 1,0 & 0,4 & $-0,1$ & 0,2 & 0,2 & 1,5 & 1,8 & 1,8 \\
\hline
\end{tabular}

Интерес вызывает задолженность по областям Центрально-черноземного района. Важно заметить, что из всех областей ЦЧР самая большая задолженность зарегистрирована на территории Воронежской области и составляет около 40\% по всей задолженности ЦЧР. Важным моментом является то, что она имеет тенденцию к снижению. Так в 2013 году задолженность составила 6,4 млрд. руб., а в 2012 году - 6,8 млрд. руб. а в 2011 - 6,2 млрд.руб. В Липецкой и Белгородской областях задолженность по налоговым платежам немного увеличилась, а в Курской и Тамбовской - имеет разнонаправленную тенденцию, но в целом снижается.

Самое маленькое количество долгов перед бюджетами всех уровней имеет Липецкая область и составляет около 8\% по всей задолженности ЦЧР, что можно увидеть на рисунке 7.

Сравнительный анализ показал, что предельная величина фискального бре- мени в аграрной сфере экономики, и ее влияние связаны не только с величиной совокупного обложения, но и с эффективностью производства и финансовым состоянием предприятия. Эффективность производства задается объемом и структурой затрат, сроком их окупаемости и полученной прибылью, что в значительной степени обусловлено сферой деятельности предпринимателя. Следовательно, предел налогообложения должен определяться с учетом отраслевой принадлежности хозяйствующих субъектов и связанных с этим объективных факторов объема и структуры расходов, скорости оборота капитала.

Таким образом, для стимулирования предпринимательской деятельности в сельском хозяйстве необходимо достижение эффективности использования налоговых инструментов. При определении предела обложения следует учитывать совокупное фискальное бремя и платежеспо- 


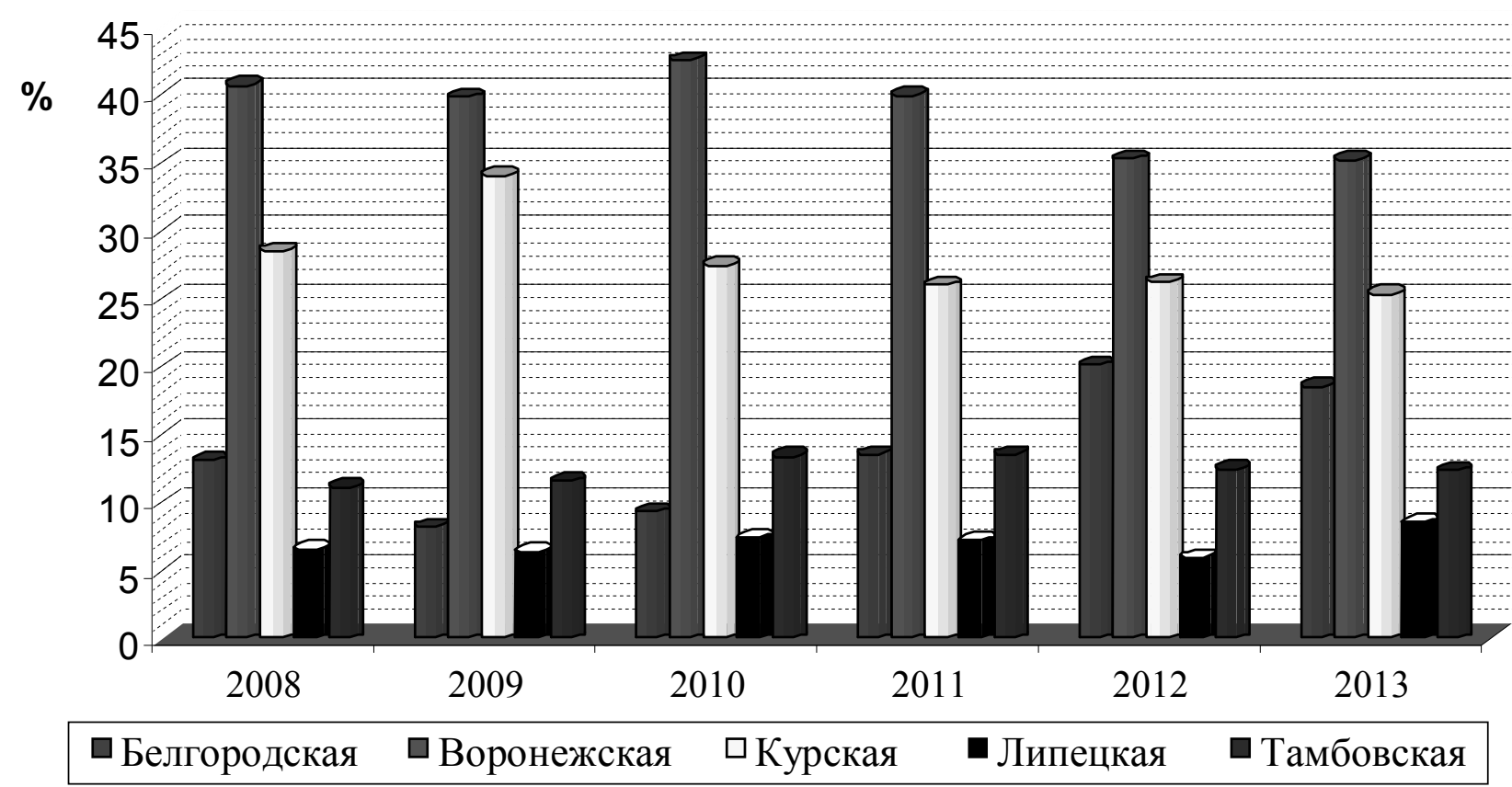

Рисунок 7 - Задолженность по налогам и сборам в областях ЦЧР, 2008-2011г., в процентах к итогу.

собность различных категорий хозяйствующих субъектов.

Проанализировав современное состояние системы налогообложения в РФ, областей ЦЧР можно сделать выводы о том, что темп роста экономики России является довольно низким, и не позволит ей в ближайшие несколько лет занять лидирующие позиции на евроазиатском пространстве и нарастить объемы экономики после присоединения к ВТО. Поступления налогов и сборов по России за анализируемый период имели тенденцию к увеличению и за 5 лет они возросли почти в 2 раза, за исключением 2009 года, где произошло значительное снижение, вследствие появления кризисных явлений. Но темпы роста налогов остаются ниже фактического уровня инфляции в стране, что говорит о фактическом снижении доходов бюджетов всех уровней.

Нам, представляется, что среди областей ЦЧР наиболее перспективное положение имеет Белгородская область, которая, несмотря на меньшие размеры и численность населения, показывает значительно лучшие результаты, чем остальные области. Хотя по сбору некоторых налогов, таких как НДФЛ, транспортный, ЕНВД и УСН, всё же уступает Воронежской области.

Динамика поступления налогов в доходную часть региональных бюджетов ЦЧР остается ниже фактического уровня инфляции в промышленности, сфере услуг и роста цен на продукцию сельского хозяйства. Что свидетельствует о фактическом снижении уровня собираемости налогов. Доходную часть бюджета Воронежской области, как и РФ, в большей мере формируют следующие налоги: налог на прибыль организаций, НДФЛ, НДС и налоги на имущество, что позволит обеспечить регион средствами для покрытия существующих расходов.

Следует отметить, что самыми приоритетными отраслями по уплате налоговых платежей в Воронежской области являются: обрабатывающие производства, торгов- 
ля, транспорт и связь, хотя по сравнению с Белгородской область, имеются резервы роста поступления налоговых платежей. Несмотря на это, Воронежская область имеет самую высокую задолженность сре- ди областей Центрально-черноземного района, хотя и наблюдается тенденция к её снижению, что свидетельствует о необходимости более тщательного контроля за учетом и взиманием налогов.

\section{Библиография:}

1. Данные по формам статистической налоговой отчетности// www.nalog.ru: сервер Федеральной Налоговой Службы России. URL: http://www.nalog.ru/nal_statistik/forms_stat.

2. Казьмин А.Г, Оробинская И.В. Анализ поступления налогов в бюд-жеты областей Центрально-Черноземного района / А.Г Казьмин, И.В Оробинская // Финансовое право и управление - Москва, № 1, 2012. - Режим доступа к журналу: http://e-notabene.ru/ flc/article_358.html

3. Налоговый кодекс Российской Федерации часть первая от 31 июля 1998 г. № 146-Ф3 и часть вторая от 5 августа 2000 г. № 117-Ф3 (с изм. и доп. от 09.09.2012 г.)//Справочно-правовая система «Гарант»: [Электр.ресурс]/НПП «Гарант-Сервис». - Послед. обновление 01.04.2014.

4. Оптимизация параметров развития производства и налогообложе-ния в интегрированных формированиях АПК: монография / А.К. Камалян, А.С. Оробинский, И.В. Оробинская, Ю.Н. Парахин; под редакцией проф. Камаляна А.К. - Воронеж: ФГОУ ВПО ВГАУ, 2010.-203 с.

5. Агузарова Л.А. Налоговый потенциал региона и повышение эффективности планирования налоговых доходов (на материалах РСО-Алания) // Налоги и налогообложение. - 2013. - 11. - С. 818-824. DOI: 10.7256/1812-8688.2013.11.10054.

6. И.В. Оробинская Эволюция становления и развития системы налогообложения сельскохозяйственных предприятий в России и зарубежных странах // Налоги и налогообложение. - 2012. - 8. - С. 54-63.

7. Гираев В.К. Региональная налоговая политика в контексте стимулирования инвестиций // Налоги и налогообложение. - 2014. - 2. - C. 124-137. DOI: 10.7256/18128688.2014.2.11187.

\section{References:}

1. Dannye po formam statisticheskoi nalogovoi otchetnosti// www.nalog.ru: server Federal'noi Nalogovoi Sluzhby Rossii. URL: http://www.nalog.ru/nal_statistik/forms_stat.

2. Kaz'min A.G, Orobinskaya I.V. Analiz postupleniya nalogov v byud-zhety oblastei Tsentral'noChernozemnogo raiona / A.G Kaz'min, I.V Orobinskaya // Finansovoe pravo i upravlenie Moskva, № 1, 2012.-Rezhim dostupa k zhurnalu: http://e-notabene.ru/flc/article_358.html

3. Nalogovyi kodeks Rossiiskoi Federatsii chast' pervaya ot 31 iyulya 1998 g. № 146-FZ i chast' vtoraya ot 5 avgusta 2000 g. № 117-FZ (s izm. i dop. ot 09.09.2012g.)//Spravochnopravovaya sistema «Garant»: [Elektr.resurs]/NPP «Garant-Servis». — Posled. obnovlenie 01.04.2014. 
4. Optimizatsiya parametrov razvitiya proizvodstva i nalogooblozhe-niya $v$ integrirovannykh formirovaniyakh APK: monografiya / A.K. Kamalyan, A.S. Orobinskii, I.V. Orobinskaya, Yu.N. Parakhin; pod redaktsiei prof. Kamalyana A.K. - Voronezh: FGOU VPO VGAU, 2010. - $203 \mathrm{~s}$.

5. Aguzarova L.A. Nalogovyi potentsial regiona i povyshenie effektivnosti planirovaniya nalogovykh dokhodov (na materialakh RSO-Alaniya) // Nalogi i nalogooblozhenie. - 2013. 11. - C. 818-824. DOI: 10.7256/1812-8688.2013.11.10054.

6. I.V. Orobinskaya Evolyutsiya stanovleniya i razvitiya sistemy nalogooblozheniya sel'skokhozyaistvennykh predpriyatii $\mathrm{v}$ Rossii i zarubezhnykh stranakh // Nalogi i nalogooblozhenie. - 2012. - 8. - C. 54-63.

7. Giraev V.K. Regional'naya nalogovaya politika v kontekste stimulirovaniya investitsii // Nalogi i nalogooblozhenie. - 2014. - 2. - C. 124-137. DOI: 10.7256/1812-8688.2014.2.11187. 